\title{
Neuro-Fuzzy Access For Detection Of Faults In An Underground Cable Distribution System
}

\author{
Garima Tiwari, Sanju Saini
}

\begin{abstract}
Nowadays, the interest of power system engineers In Indian Power System has increased towards the use of underground cables with the advent of cross-linked polyethylene (XLPE) insulated cables having high capacity for transmission of power. Underground cables are preferred in the densely populated regions where there is environmental constraint and right of way poses a big problem. The key limitation of underground cable is to locate and detect different types of faults in view of the fact that the cables are lying down under the surface. It is necessary that the fault must be cleared in minimum time on account of protection issues. As conventional methods for detection and classification of faults are time consuming, so, this work uses intelligent techniques for fast and more accurate detection of location and classification of faults in underground cables.

Overall work has been performed in three steps, the first step is to develop a MATLAB/Simulink Model of a distribution system using underground cable with a provision to develop fault. In second step, an Artificial Neural Network (ANN) using DWT is used for fault detection \& classification. In third step, ANN is hybridized with fuzzy system and discrete wavelet transform (DWT) methods to improve its performance. The training sets of adaptive neuro fuzzy inference system (ANFIS) are energy components of three phases of cable under fault (used as inputs) and fault type or different distances of faults in the cable(used as outputs). All the simulations have been carried out in MATLAB/ SIMULINK environment.
\end{abstract}

Keywords:- Underground Cables, Fault detection, Adaptive neuro fuzzy inference system (ANFIS),

\section{INTRODUCTION}

Recently, the use of underground cable system is expanding on account of the requirement of enhanced reliability and safety considerations in the distribution systems[1]. To improve the reliability of a distribution system, it becomes necessary to identify the faulted segment accurately and rapidly so as to decrease the interruption period on occurrence of a fault[2]. This also becomes necessary to reduce the financial losses and outage time. But, detection of location of a fault is a challenging job for underground cables (due to their inaccessibility). Classical fault locating techniques can not be used for underground cables due to a number of disadvantages e.g., acoustic method is cumbersome and may be disastrous during rain and Murray loop method is less accurate[1]. It is not possible to do the checking of UG (underground) cables section wise so Sectionalizing method can not be employed [1]. Methods based on travelling wave are sensitive to the noise and faults

Revised Version Manuscript Received on August 19, 2019.

Garima Tiwari, Department of Electrical Engineering, DCRUST, Murthal, Haryana , India(Email: agarimatiwari53@gmail.com)

Dr.Sanju Saini, Department of Electrical Engineering, DCRUST, Murthal, Haryana , India(Email: bsanjusaini.ee@dcrustm.org) which occur in close proximity in the lines[2] .

Changes in System's parameters do not affect the performance of Artificial intelligent techniques. Due to superior learning and generalizing capabilities (from

training patterns), these techniques have been utilized by a number of researchers for optimization, Control \& forecasting engineering problems[3-6]. An artificial neural network (ANN) mimics the human brain by learning from environment and then responds accordingly. ANN (Artificial neural networks) has been used by a number of researchers for developing complete schemes for the detection, classification as well as finding location of fault $[1,2,7-8]$. However, for fault classification, ANN alone cannot give very accurate results and a large number of neural networks are required for different categories of faults [9]. Moreover, ANN and fuzzy logic approaches are also sensitive to the System's frequency-Changes.

.Recently, the techniques of wavelet transform have been used effectively for representation (multi-scale) and analysis of power system transients [10-13]. This technique decomposes the transients in various components. Each of them is corresponding to a signal in time domain (covering a particular energy band). Thus, wavelets are used for localizing information.

ANFIS is an ANN (Artificial Neural Network) based on a Fuzzy Inference System (Takagi-Sugeno type). Developed in early 1990s, it combines the principles of both the artificial neural networks and fuzzy logic., So, It can capture their benefits in one framework. Its inference system has a set of fuzzy IF-THEN rules having ability to learn nonlinear functions (approximate). Present paper uses a DWT-ANFIS based approach for fault detection in an Underground Cable Distribution System. The proposed scheme is validated for twelve (different) faults conditions occurring at ten (different) locations. MATLAB model of the underground distribution system is given in next section followed by the methodology used. Further simulation results are given in Section IV followed by Conclusions and list of References.

\section{MODEL OF UNDERGROUND CABLE DISTRIBUTION SYSTEM}

MATLAB is used for modeling the underground cable as PI section and its overall Simulink model of the is given in Fig.1. Simulink model has facility to create eleven types of faults i.e. each line(A or $B$ or $C$ ) to ground $(G)$ short circuit (i.e., $\mathrm{AG}$ or $\mathrm{BG}$ or $\mathrm{CG}$ faults ), each line (A, B or C) to other 


\section{NEURO-FUZZY ACCESS FOR DETECTION OF FAULTS IN AN UNDERGROUND CABLE DISTRIBUTION SYSTEM}

line (A, B or C) short circuit (i.e., $\mathrm{AB}$ or $\mathrm{AC}$ or $\mathrm{BC}$ faults ), each line $(\mathrm{A}, \mathrm{B}$ or $\mathrm{C})$ to other line $(\mathrm{A}, \mathrm{B}$ or $\mathrm{C})$ to ground $(\mathrm{G})$ short circuit (i.e., ABG or ACG or BCG faults) , All

three-phases short circuit (i.e., ABC fault), All three phases and ground short circuit(i.e., ABCG fault).

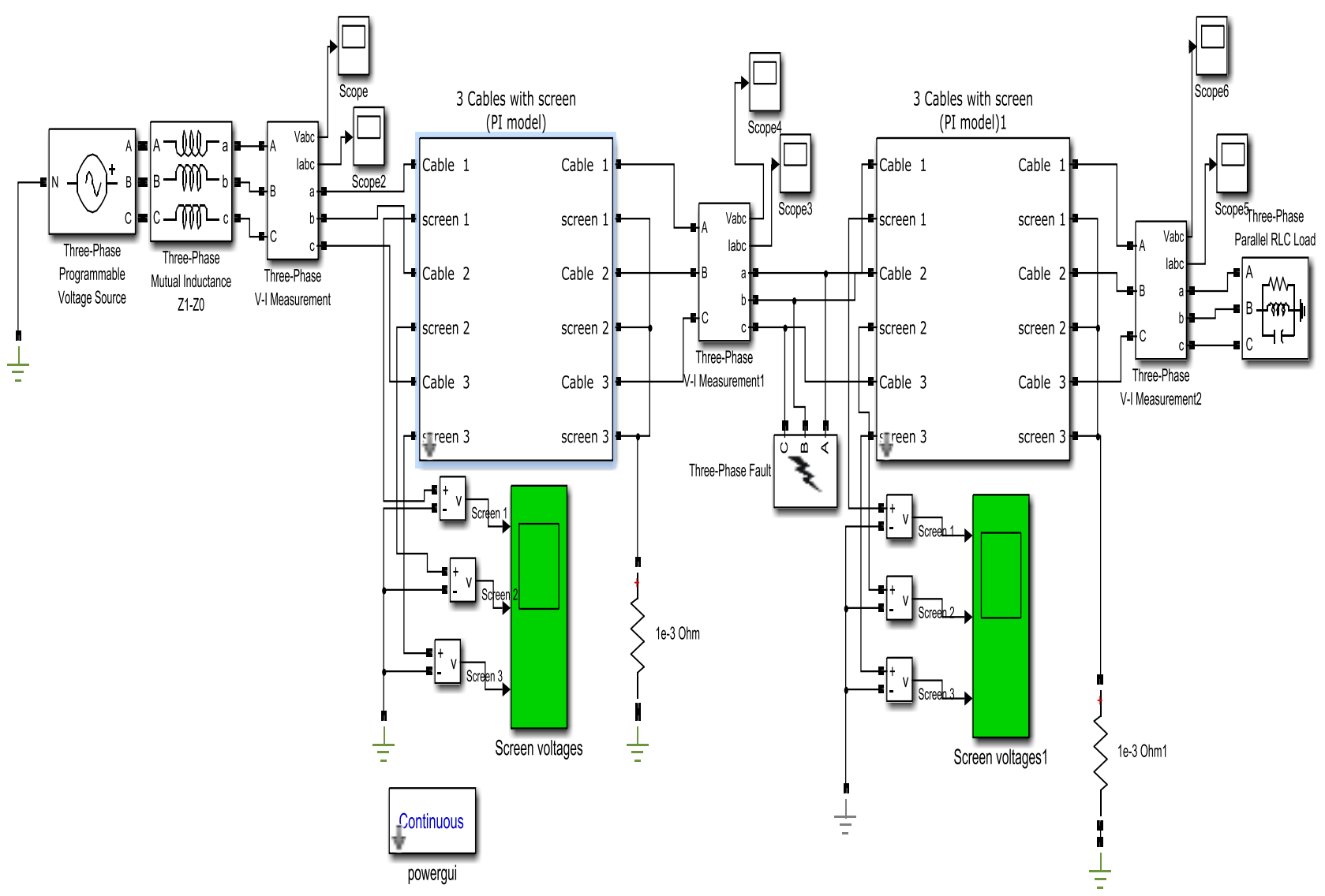

Fig 1 Simulink model of cable

The parameters used for underground cable are given in TABLE 1 . Voltage of three phase voltage source is $11 \mathrm{kv}$ at a frequency of $50 \mathrm{~Hz}$.

TABLE 1

Configuration Parameters of Cable

\begin{tabular}{|c|c|c|}
\hline S. no. & PARAMETERS & VALUES \\
\hline 1) & Number of cables & 3 \\
\hline 2) & Frequency & $50 \mathrm{~Hz}$ \\
\hline 3) & Ground resistivity & $100 \circ \mathrm{oh}^{*} \mathrm{~m}$ \\
\hline 4) & $\begin{array}{l}\text { The geometric mean } \\
\text { distance between cables }\end{array}$ & $80.09 \mathrm{~cm}$ \\
\hline 5) & Phase conductor & \\
\hline 6) & Number of strands & 58 \\
\hline 7) & Strand diameter & $2.7 \mathrm{~mm}$ \\
\hline 8) & Resistivity & $1.78 \mathrm{e}-8 \mathrm{ohm} \mathrm{m}^{*} \mathrm{~m}$ \\
\hline 9) & Relative Permeability & 1 \\
\hline 10$)$ & External diameter & 20.9 \\
\hline 11) & Phase-Screen Insulator & \\
\hline 12) & Relative Permeability & 2.3 \\
\hline 13) & Internal diameter & $23.3 \mathrm{~mm}$ \\
\hline 14) & External diameter & $66.6 \mathrm{~mm}$ \\
\hline 15) & Screen Conductor & \\
\hline 16) & Resistivity & $1.78 \mathrm{e}-8 \mathrm{ohm} \mathrm{m}^{*} \mathrm{~m}$ \\
\hline 17$)$ & Total section & $0.000169 \mathrm{~m}^{\wedge} 2$ \\
\hline 18) & Internal diameter & $65.8 \mathrm{~mm}$ \\
\hline 19) & External diameter & $69.8 \mathrm{~mm}$ \\
\hline 20$)$ & Outer Screen Insulator & \\
\hline 21) & Relative Permittivity & 2.25 \\
\hline 22) & internalDiameter & $69.8 \mathrm{~mm}$ \\
\hline 23) & external Diameter & $77.8 \mathrm{~mm}$ \\
\hline
\end{tabular}

\section{METHODOLOGY}

The method used for fault detection and classification mainly consists of two objectives, i.e., detection of type of fault and estimation of location of fault. Detection of type of fault is first done with help of an artificial Neural Network. For each type of the fault, a separate artificial Neural Network (ANN) is used for estimation of fault location (i.e., 11 ANNs are used for this purpose).To improve the results, each ANN is replaced by ANFIS .in the second stage of simulation.

\section{A) Use of DWT for extraction of features}

In this work, fault voltage signals have been used as input to discrete wavelet transform (DWT). On account of high performance, daubechies DB4 wavelet has been employed. Fault transients have been analyzed by using DWT (at level eight). Effect of fault in the cable can be noted as variations in decomposition coefficient of fault voltage signals, which contain useful information about faults.

While studying the DWT detailed coefficients (from levels 1-8) for a particular fault, it is observed that level 8 detailed coefficient has a side band along with dominant spike during fault initiation process. This side band is not observed for 
lower level coefficients. It is also observed that the nature of this side band (along with dominant spike) changes considerably with changes in type and location of the faults . Hence, the maximum detailed energy (At level-8) of three-phase voltages is used as features. The proposed method trains the ANN/ANFIS system with a fault database (obtained from cable model simulation).

TABLE 2

Target Vector for fault classification

\begin{tabular}{|l|c|}
\hline \multicolumn{1}{|c|}{ PARAMETERS } & VALUES \\
\hline Phase A to ground short circuit (AG) & 1 \\
\hline Phase B to ground short circuit (BG) & 2 \\
\hline Phase C to ground short circuit(CG) & 3 \\
\hline Phase A to Phase B short circuit (AB) & 4 \\
\hline Phase B to Phase C short circuit(BC) & 5 \\
\hline Phase A to Phase C short circuit(AC) & 6 \\
\hline Phase A to Phase B to ground short crcuit(ABG) & 7 \\
\hline Phase B to Phase C to ground short cicuit(BCG) & 8 \\
\hline Phase A to Phase C to ground short circuit (ACG) & 9 \\
\hline Phase A to Phase B to Phase C short circuit(ABC) & 10 \\
\hline $\begin{array}{l}\text { Phase A to Phase B to Phase C to ground short circut } \\
\text { (ABCG) }\end{array}$ & 11 \\
\hline No Fault & 12 \\
\hline
\end{tabular}

\section{B)Target Vector for fault classification}

For fault type classification, the target vector used for ANN/ANFIS is shown in TABLE 2.

C) Target Vector for fault location estimation

For fault location estimation, Target vectors for training \& testing purposes are given, in TABLE 3 .

TABLE 3

Target Vector for fault classification

\begin{tabular}{|c|c|}
\hline $\begin{array}{c}\text { TRAINING } \\
(\mathrm{km})\end{array}$ & $\begin{array}{c}\text { TESTING } \\
(\mathrm{km})\end{array}$ \\
\hline 0 & 3 \\
\hline 4 & 5 \\
\hline 8 & 11 \\
\hline 10 & \\
\hline 12 & \\
\hline 16 & \\
\hline 18 & \\
\hline
\end{tabular}

\section{SIMULATION RESULTS}

A twenty kilometer long underground cable system is modeled by using MATLAB/SIMULINK model as explained in Section I. It has provision to apply fault at different location and measures voltage and current. The run time (of simulation) is 0.08 seconds whereas switching time of the circuit breaker has been taken as $0.02 \mathrm{sec}$ to $0.03 \mathrm{sec}$. To find fundamental values of fault voltage and current, Fourier block has been used for each phase.

\section{A. Collection of Training Data}

To get the training data for ANN/ANFIS, values of fault voltages and currents (for all types of faults) are measured from the SIMULINK model of the underground cable. On account of limited paper space, such values are represented in TABLE 4 for line to ground fault only.

TABLE 4

Fault Voltages \& Currents

\begin{tabular}{|c|c|c|c|}
\hline Quantfes & $\begin{array}{l}\text { Line To Grodnd } \\
\text { FaultAt PhaseA }\end{array}$ & $\begin{array}{l}\text { Line To Ground } \\
\text { Fault AtPhase B }\end{array}$ & $\begin{array}{l}\text { Line To Ground } \\
\text { FaultAtPhaseC }\end{array}$ \\
\hline Vsa & $0.0025-0.0003 j$ & $0.0247 \cdot 0.00191 j$ & $0.0210-0.0082 j$ \\
\hline$V_{5 b}$ & $-0.0178-0.0141 \mathrm{j}$ & $-0.00159-0.00209]$ & $-0.014-0.020 \mathrm{j}$ \\
\hline VSC & $\begin{array}{l}-0.0107 \\
+0.0223 \mathrm{j}\end{array}$ & $-0.0034+0.0223 j$ & $-0.0010+0.0023 j$ \\
\hline 50 & $0.4528-1.828 \mathrm{j}$ & $0.6584-0.00184 j$ & $0.5280-0.204 j$ \\
\hline 56 & $-0.4407-0.355 j$ & $-1.964+0.528 \mathrm{j}$ & $-0.3310-0.5701 \mathrm{j}$ \\
\hline SC & $-0.327+0.5721 \mathrm{j}$ & $-0.0875+0.559 \mathrm{j}$ & $1.55 \mathrm{~b}+1.3 \mathrm{j}$ \\
\hline Vra & $0.00035+0.0005 j$ & $0.026-0.0026 j$ & $0.0201-0.0102 j$ \\
\hline Vro & $-0.018-0.123 \mathrm{j}$ & $0.000253-0.00056]$ & $-0.01528-0.0212 j$ \\
\hline$V_{N}$ & $-0.0107+0.0238 \mathrm{j}$ & $-0.00124+0.0226 \mathrm{j}$ & $-0.00061+0.00008$ \\
\hline $\mathrm{ra}$ & $0.0089+0.0125 \mathrm{j}$ & $0.6528-0.085 j$ & $0.5051-0.2556 \mathrm{j}$ \\
\hline Tro & $-0.4738-0.309 j$ & $0.00828 \cdot 0.0140 \mathrm{j}$ & $-0.382-0.53 j$ \\
\hline To & $-0.2096+0.598 \mathrm{j}$ & $-0.03104+0.5654 j$ & $-0.0153+0.00148 j$ \\
\hline
\end{tabular}

\section{B. Training Data via Simulation}

Input training data to ANN/ANFIS are energy components of detailed coefficients of wavelet transformed fault voltages; i.e. Ea, Eb, Ec respectively. Training data of ANN/ANFIS for fault types and fault location detection have been shown in TABLE 5 \& TABLE 6 respectively.

TABLE 5

Energy component of three phases for different types of faults (fault occurring at a distance of $4 \mathrm{Kms}$ )

\begin{tabular}{|l|l|l|c|}
\hline Ea & Eb & EC & $\begin{array}{l}\text { Type of } \\
\text { fault }\end{array}$ \\
\hline 0.8860 & 0.0444 & 0.0365 & AG \\
\hline 0.0223 & 0.8928 & 0.0431 & BG \\
\hline 0.0010 & 0.0049 & 6.7797 & CG \\
\hline 0.8888 & 0.8897 & 0.0036 & ABG \\
\hline 0.0260 & 0.8931 & 5.9938 & BCG \\
\hline 0.8871 & 0.0263 & 39.663 & ACG \\
\hline 0.5445 & 0.6316 & 0.0094 & AB \\
\hline 0.5623 & 0.6184 & 0.0086 & BC \\
\hline 0.0086 & 0.0088 & 0.5555 & AC \\
\hline 0.9016 & 0.9022 & 4.9516 & ABC \\
\hline 4.9516 & 0.8954 & 2.0490 & ABCG \\
\hline 7.8626 & 4.7810 & 44.4286 & NOFAULT \\
\hline
\end{tabular}


TABLE 6

Energy component of three phases for a different locations of fault (for phase A to ground fault)

\begin{tabular}{|l|l|l|c|}
\hline Ea & Eb & Ec & $\begin{array}{l}\text { Type of } \\
\text { fault }\end{array}$ \\
\hline 0.8860 & 0.0444 & 0.0365 & AG \\
\hline 0.0223 & 0.8928 & 0.0431 & BG \\
\hline 0.0010 & 0.0049 & 6.7797 & CG \\
\hline 0.8888 & 0.8897 & 0.0036 & ABG \\
\hline 0.0260 & 0.8931 & 5.9938 & BCG \\
\hline 0.8871 & 0.0263 & 39.663 & ACG \\
\hline 0.5445 & 0.6316 & 0.0094 & AB \\
\hline 0.5623 & 0.6184 & 0.0086 & BC \\
\hline 0.0086 & 0.0088 & 0.5555 & AC \\
\hline 0.9016 & 0.9022 & 4.9516 & ABC \\
\hline 4.9516 & 0.8954 & 2.0490 & ABCG \\
\hline 7.8626 & 4.7810 & 44.4286 & NOFAULT \\
\hline
\end{tabular}

Structure of Artificial neural, used in this work consists of five layers; input layer, 3 hidden layers and output layer. In ANN training, neurons in hidden layers play the vital role. Here, three hidden layer's neurons are 5, 5, 1 respectively (Decided by extensive trial simulations). Other parameters of ANN are shown in Fig. 2.

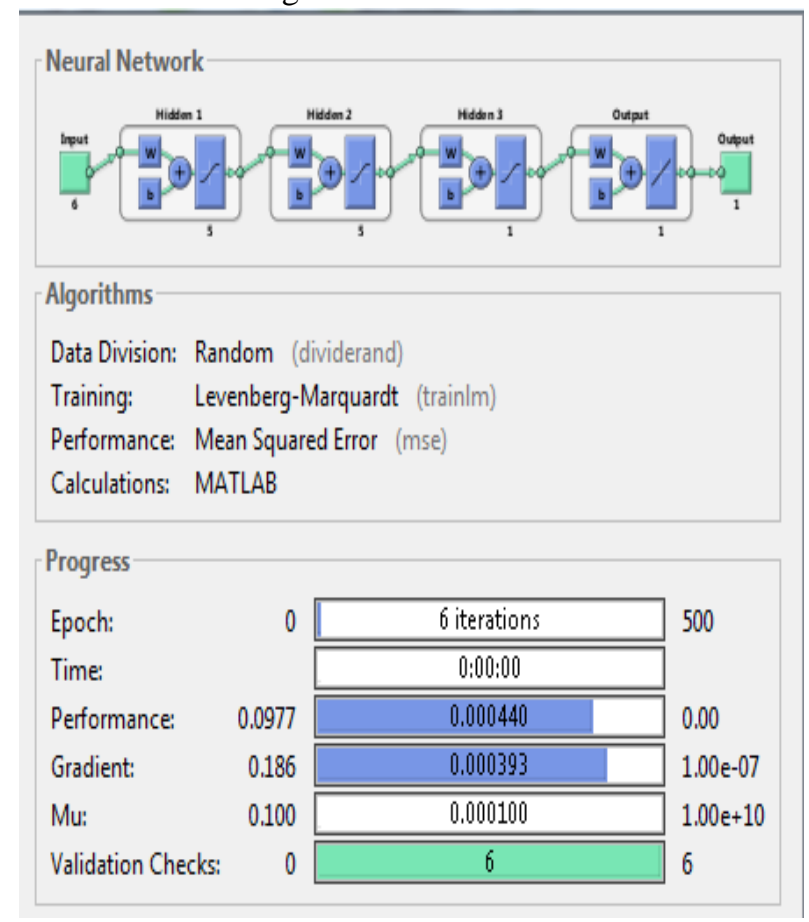

Fig. 2 Training of data using ANN

While using ANFIS, after loading training data, grid pattern method has been used to generate fuzzy inference system. ANFIS toolbox of MATLAB is given (in Fig. 3).

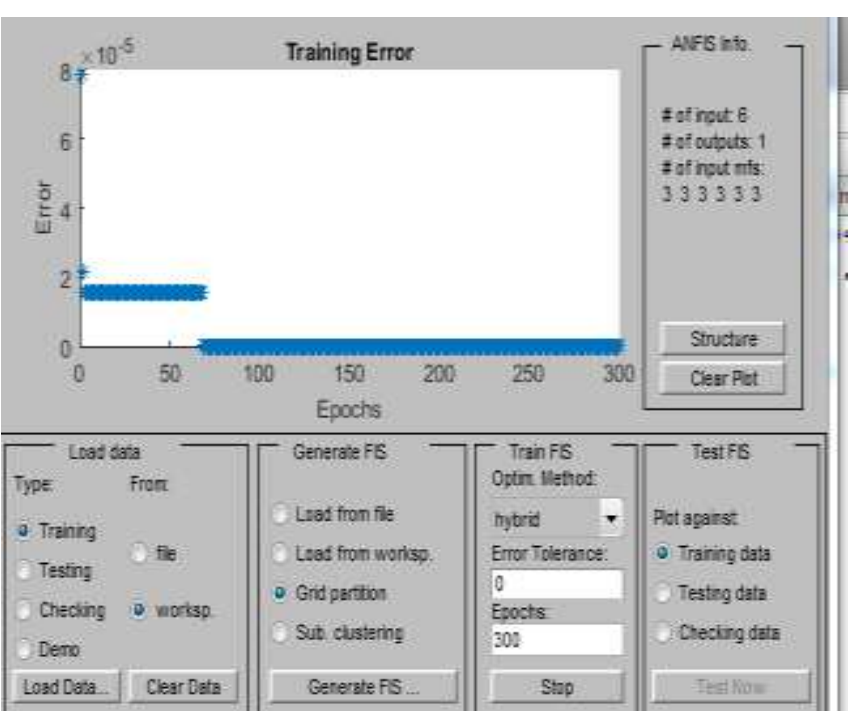

Fig. 3 Training of data using ANFIS

After generating FIS (Fuzzy Inference System), ANFIS is trained by using a hybrid method in which least square estimation and the gradient descent method is combined with Runge Kutta learning method. Error tolerance and epoch used for ANFIS training are ' 0 ' and 300 respectively.

\section{Error Calculations for Training data \& Testing Data}

After training, the percentage errors are calculated for training data in case of ANN and ANFIS (as shown in TABLE 7). It is dependent upon the actual output and desired output from ANN/ANFIS and is calculated by using eqns. 1 $\& 2$ for fault type and fault locations respectively.

$* \%$ Error $=[($ Expected Output- Actual Output $) /$ Expected Output] $* 100$

$* \%$ Error $=[($ Exact location- Estimated location $) /$ Total length of cable]*100

TABLE 7

Comparative errors of ANN and ANFIS

\begin{tabular}{|c|c|c|}
\hline Methods & $\begin{array}{c}\text { Maximum Error } \\
\text { in types of fault }\end{array}$ & $\begin{array}{c}\text { Maximum Error in } \\
\text { location of fault }\end{array}$ \\
\hline ANN & $6 \%$ & $1.996 \%$ \\
\hline ANFIS & $0.011 \%$ & $0.00235 \%$ \\
\hline
\end{tabular}

Thus, a considerable reduction in error is obtained by use of ANFIS for training data. Then, the percentage errors are calculated for testing/random data in case of ANFIS (as shown in TABLE 8). Maximum error in this case is also less than $3.1 \%$. 
TABLE 8

Percentage error of ANFIS for testing/random data

\begin{tabular}{|c|c|c|c|}
\hline \multirow{2}{*}{$\begin{array}{c}\text { Type of } \\
\text { faults }\end{array}$} & \multicolumn{3}{|c|}{ PERCENTAGE ERRORS } \\
\cline { 2 - 4 } & $\begin{array}{c}\text { Fault at } \\
3 \mathrm{~km}\end{array}$ & $\begin{array}{c}\text { Fault at } \\
5 \mathrm{~km}\end{array}$ & $\begin{array}{c}\text { Fault at } \\
11 \mathrm{~km}\end{array}$ \\
\hline BG & $1.3 \%$ & $1.9 \%$ & $2 \%$ \\
\hline ABG & $2.6 \%$ & $1.4 \%$ & $2.7 \%$ \\
\hline AB & $3 \%$ & $2.8 \%$ & $3.1 \%$ \\
\hline
\end{tabular}

\section{CONCLUSION}

In this paper, An ANFIS is used efficiently for classification \& localization of fault in a Cable Distribution System. The model uses three post-fault voltage values as inputs and DWT has been used for feature extraction. As an aspect of future scope, one can go ahead by simulating the model by using other techniques (simulation) like PSCAD, Alternative Transient Programmer (ATPDraw) etc. Training of ANFIS used can be made more efficient by use of metaheuristics like genetic algorithms, etc.

\section{REFERENCES}

1. Kunal Hasija, Abhishek Kumar, Shelly Vadhera and Anurag Kishore, "Detection and location of faults in inderground cable usingMatlab/Simulink/ANN and OrCad", in Proceedings of IEEE Power India International Conference, Delhi, pp. 1-5,(2013).

2. Ankita Nag, Anamika Yadav, "Fault classification using Artificial Neural Network in combined underground cable and overhead line", in Proceedings of IEEE Power Electronics Intelligent Control and Energy Systems International Conference, pp. 1-4, (2016).

3. S.Saini, M.Ahuja, " Wind Speed Prediction Using Wavelet transform and Artificial Neural Network". International Journal of Researchin Electronics And Computer Engineering, vol.5(4), pp.161-168, (2017).

4. Sanju Saini, Sarita Rani, "Temperature Control Using Intelligent Techniques", Second IEEE International Conference on Advanced Computing \& Communication Technologies, Rohtak, Haryana, India, pp. 138-145 (2012)

5. Sanju Saini, Dr. J. S. Saini, "GA Optimized Time Delayed Feedback Control of Chaos in a Memristor Based Chaotic Circuit", IEEE Symposium on Computational Intelligence for Engineering Solutions (CIES), Orlando, USA, pp. 74-80 ( 2014)

6. Hitesh Kumar, Sanju Saini, "Chaotic Characterization of Electric Load Demand Time Series \& load forecasting by using GA trained Artificial Neural Network", Proceedings of IEEE International conference on Signal Processing, Communication, Power and Embedded System , Odisha, India, pp. 1423-28, (2016).

7. M. Oleskovicz, D.V. Coury, R.K. Aggrawal, "A Complete Scheme for Fault Detection; Classification and Location in Transmission Lines using Neural Networks", in Proceedings of IEEE Seventh International Conference on Developments in Power System Protection , Amsterdam, Netherlands, pp. 335-338, (2001)

8. Moez Ben Hessine, Houda Jouini, Souad Chebbi "Fault Detection and Classification Approaches in Transmission Lines Using Artificial Neural Networks", in Proceedings of 17th IEEE Mediterranean Electrotechnical Conference, Beirut, Lebanon, pp. 515-519, (2014).

9. Samantaray, S.R., "A systematic fuzzy rule based approach for fault classification in transmission lines",
Applied Soft Computing, 13, pp. 928-938, (2013).

10. Hanif Livani, and C. Yaman Evrenosoglu, " A machine learning and wavelet based fauIt location method for Hybrid Transmission Line", in Proceedings of IEEE PES T\&D Conference, Chicago, IL, USA, (2014).

11. D.C. Robertson , O.I. Camps, J.S. Mayer ; W.B. Gish, "Wavelets and electromagnetic power system transients", IEEE Transactions on Power Delivery , 11 (2) , pp. 1050-1058, (1996).

12. V. Kale, S. Bhide, and P. Bedekar, "Faulted phase selection on double circuit transmission line using wavelet transform and neural network," in Proceedings of IEEE International Conference on Power Systems, Kharagpur, India , pp. 1-6, (2009).

13. W. Zhao, Y. Song, and Y. Min, "Wavelet analysis based scheme for fault detection and classification in underground power cable systems," Electric Power Systems Research, vol. 53, pp. 23-30, (2000). 